UDC 519.632; 539.182

\title{
Solving the eigenvalues and eigenfunctions problems for the Helmholtz equation by the point-sources method*
}

\author{
E. E. Shcherbakova** \\ Don State Technical University, Rostov-on-Don, Russian Federation
}

The paper provides the developed approach to solve the eigenvalues and eigenfunctions problems for the Helmholtz equation in domains with an arbitrary configuration. In developing the approach for numerical solution of problems, the point-sources method (PSM) was used. The proposed method is based on the analysis of the condition number of the PSM system or the error of the numerical solution of problems. The concept of "eigenvalues criteria" is introduced. The research result is a developed effective method - an algorithm for solving problems of eigenvalues and eigenfunctions for the Helmholtz equation. It is shown that at the approach of the Helmholtz parameter to the problem eigenvalue, the condition number of the PSM system and the error of the numerical solution rise sharply. Therefore, we calculate the dependence of the condition number of the PSM system or error of the problem numerical solution on the Helmholtz parameter. Then, according to position of the maximum of the received dependences we find the eigenvalues of the Helmholtz equation in a given domain.. After finding the eigenvalues, it is possible to proceed to the determination of the eigenfunctions. At that, if the eigenvalue appears degenerate, that is some eigenfunctions correspond to it, then it is possible to find all the eigenfunctions taking into account the symmetry of the solution domain. The two-dimensional and three-dimensional test problems are solved. Upon the results obtained, the conclusion about the efficiency of the proposed method is made.

Keywords: point-sources method, eigenvalues, eigenfunctions, Helmholtz equation, fundamental solution, the method of fundamental solutions.

Introduction. A number of problems of mathematical physics, having great practical importance in the development of electro-mechanical devices, lead to the decision of the Helmholtz homogeneous equation

$$
\Delta U(\mathbf{r})+\lambda U(\mathbf{r})=0
$$

with a positive value of the Helmholtz parameter $\lambda>0$. This is a broad class of problems related to the steady-state oscillations (mechanical, acoustic, thermal, electromagnetic, etc.). Numerical solution of mass and heat transfer problems also leads to the Helmholtz equation, having a negative value of the parameter $\lambda<0$. The importance of the Helmholtz equation is also conditioned the fact that all elliptic equations with constant coefficients are equivalent to the equation of this kind.

Solution to a number of applied problems required to find the eigenvalues and eigenfunctions for the Laplace equation in domains with a different configuration. The analytical solution to such problems, and numerical solution using traditional numerical methods, can cause considerable

\footnotetext{
* The research is done within the frame independent R\&D.

** E-mail: Sherbakovaee@mail.ru
} 
difficulties and are not always advisable especially if a domain of the solution has a complicated configuration, and the boundary conditions include the normal derivative.

One of the most effective methods for the numerical solution to boundary value problems for elliptic equations is the point-sources method (PSM) [1-7]. This method is used in the simulation of electrical, magnetic, thermal, concentration, elastic stress and other physical fields [8-17]. PSM advantage is its simplicity, and a much smaller amount of computation in comparison with traditional numerical methods for solving boundary value problems, such as, for example, a finite element method (FEM). Application of PSM can be justified as in the problems solution of eigenvalues for elliptic equations, for example, the Helmholtz equation [18, 19], the Schrödinger equation $[20,21]$.

Description of the numerical method. Suppose that in $\Omega$ domain Helmholtz equation (1) is performed, and on $\partial \Omega-\Omega$ domain boundary condition type is defined

$$
\left.\left(\alpha(\mathbf{r}) \frac{\partial U}{\partial n}+\beta(\mathbf{r}) U\right)\right|_{\partial \Omega}=\left.\gamma(\mathbf{r})\right|_{\partial \Omega},
$$

where $\alpha, \beta, \gamma$-continuous functions defined on the boundary $\partial \Omega$ domain $\Omega$.

For finding unknown function $U(\mathbf{r})$ PSM may be used. For this purpose $N$ nodes were located on the boundary $\partial \Omega$ at points with coordinates $\mathbf{r}_{i}$. Around the domain $\Omega$, at some distance from its border, are located $N$ point sources of the field with the charges $q_{j}$, at points with coordinates $\mathbf{R}_{j}$. The defined field is approximately represented as a sum

$$
U(\mathbf{r})=\sum_{j=1}^{N} q_{j} g\left(\mathbf{r}, \mathbf{R}_{j}\right),
$$

where $\mathrm{g}\left(\mathbf{r}, \mathbf{R}_{j}\right)$ - the fundamental solution of the Helmholtz equation. In three-dimensional version.

$$
g(\mathbf{r}, \mathbf{R})=\frac{\exp ( \pm \sqrt{\lambda}|\mathbf{r}-\mathbf{R}|)}{4 \pi|\mathbf{r}-\mathbf{R}|} .
$$

The solution to the problems of two-dimensional fundamental solutions [22], is expressed in terms of modified Bessel functions of the second kind (if $\lambda<0$ ):

$$
g(\mathbf{r}, \mathbf{R})=\frac{1}{2 \pi} K_{0}(\sqrt{-\lambda}|\mathbf{r}-\mathbf{R}|),
$$

or through the Hankel function of the first kind of zero order (when $\lambda>0$ ):

$$
g(\mathbf{r}, \mathbf{R})=\frac{i}{4} H_{0}^{(1)}(\sqrt{\lambda}|\mathbf{r}-\mathbf{R}|)
$$

Sign in $\left(4_{1}\right)$ is selected depending on the specific features of the problem being solved. Depending on the sign of the parameter $\lambda$, exponent argument in the expression $\left(4_{1}\right)$ will be either real or imaginary number.

When $\lambda=0$, the equation (1) degenerates into the Laplace equation and the fundamental solution $\left(4_{1}\right)$ for three-dimensional problems takes the form $g(\mathbf{r}, \mathbf{R})=1 /(4 \pi \mid \mathbf{r}-\mathbf{R})$; accordingly for two-dimensional problems 


$$
g(\mathbf{r}, \mathbf{R})=\frac{1}{2 \pi} \ln \frac{1}{|\mathbf{r}-\mathbf{R}|} .
$$

The solution $\mathrm{g}(\mathbf{r}, \mathbf{R})$ can be considered as a potential field, created at the point $\mathbf{r}$, by unit point charge, located at $\mathbf{R}$. For any charge values $q_{j}$, function $U(\mathbf{r})$ satisfies the Helmholtz equation (1). It is necessary to choose the charges $q_{j}$ so that the boundary conditions (2) are performed in all the $N$ boundary nodes. For the node with number $i$, the condition (2) can be written as

$$
\sum_{j=1}^{N} q_{j}\left(\alpha\left(\mathbf{r}_{i}\right) \frac{\partial g\left(\mathbf{r}_{i}, \mathbf{R}_{j}\right)}{\partial n}+\beta\left(\mathbf{r}_{i}\right) g\left(\mathbf{r}_{i}, \mathbf{R}_{j}\right)\right)=\gamma\left(\mathbf{r}_{i}\right) .
$$

As a result, writing the equation (5) for all $N$ nodes, we obtain a system of linear algebraic equations, the PSM system. After the solution of the system (5), the unknown field $U(\mathbf{r})$ is approximately expressed by the formula

$$
U(\mathbf{r})=\sum_{j=1}^{N} q_{j} g\left(\mathbf{r}, \mathbf{R}_{j}\right) .
$$

It is known, that for some positive values of the parameter $\lambda$, the boundary value problem (1)-(2) for the homogeneous Helmholtz equation with homogeneous boundary conditions $(\gamma(\mathbf{r}) \equiv 0)$ may have a non-zero solution. Finding these parameter values $\lambda=\lambda_{n}$, eigenvalues, and the corresponding solutions, the eigenfunctions of the boundary value problem, is the main purpose of this paper.

When $\gamma(\mathrm{r}) \equiv 0$, PSM system is the system of homogeneous linear algebraic equations. As it is known, for the existence of a nonzero solution of this system it is necessary that its determinant is equal to zero. However, the rounding errors in calculating the determinant, leads to the fact that the approach of the parameter $\lambda$ to some of their eigenvalues, there is a sharp decrease in the absolute value of the determinant (instead of its conversion to zero) and, accordingly, a sharp increase in the condition number of the PSM system. It, therefore, leads to a sharp increase in the error of the numerical solution of the boundary value problem.

Thus, the eigenvalues of the problem can be approximately installed in the calculation dependence of the determinant, or the condition number of the PSM system, or error in the numerical solution of the boundary value problem, from the Helmholtz parameter $\lambda$. Let us call these parameters as criteria of eigenvalues.

When the eigenvalue is found, it is possible to determine the eigenfunctions corresponding to this eigenvalue problem boundary value. It is possible to proceed as follows. Set ready $U_{0}(\mathbf{r})$ solution for the homogeneous Helmholtz equation. Such decision can be an expression corresponding to the field of a point charge $Q\left(4_{2}\right)$, located outside the solution domain of boundary value problem. The values of this field in $\partial \Omega$ boundary of the domain $\Omega$ are used as a right-hand member of equation in the boundary condition (2). The solution boundary value problem obtained by using PSM, when value of the parameter $\lambda$ is equal to one of the eigenvalues $\lambda=\lambda_{n}$, and can be represented as the sum of $U(\mathbf{r})=U_{0}(\mathbf{r})+u(\mathbf{r})$, where $u(\mathbf{r})$ - eigenfunction, eigensolution, corresponding to a given eigenvalue. It follows that the proper function will be equal to the difference between the solution of the 
boundary problem, obtained by PSM, and the given decision $U_{0}(\mathbf{r})$ of the homogeneous Helmholtz equation:

$$
u(\mathbf{r})=U(\mathbf{r})=U_{0}(\mathbf{r})
$$

Of course, the accuracy of such a decision, due to ill-conditioning of the PSM system, may not be very high. However, as it will be shown below, this accuracy is usually quite acceptable.

Usually, some eigenfunctions of the boundary value problem correspond to the given eigenvalue. In this case it is possible to find all eigenfunctions, corresponding to a given $\lambda_{n}$. For this purpose, using the method described above, we find eigenfunctions, corresponding to different locations of the charge $Q$, created the field $U_{0}(\mathbf{r})$. Then, if necessary, between the obtained eigenfunctions produce orthogonalization.

Test example of finding the eigenvalues for two-dimensional problem. As an example, we consider the test to find the eigenvalues and eigenfunctions of the Dirichlet problem for the homogeneous Helmholtz equation in a circular domain of radius $r_{0}$. It is known [23], the eigenvalues for this problem have the form

$$
\lambda_{n m}=\frac{\mu_{n m}^{2}}{r_{0}^{2}},
$$

where $\mu_{n m}$ - positive roots of the transcendental equation $J_{n}(\mu)=0 ; J_{n}(\mu)$ - Bessel function of order $n, n=0,1,2, \ldots ; m=1,2,3, \ldots$

Two eigenfunctions correspond to each $n>0$ :

$$
u_{n m}^{(1)}(\mathbf{r})=J_{n}\left(r \sqrt{\lambda_{n m}}\right) \cos n \varphi, \text { и } u_{n m}^{(2)}(\mathbf{r})=J_{n}\left(r \sqrt{\lambda_{n m}}\right) \sin n \varphi
$$

For $n=0$ the eigenfunctions have axial symmetry and equal

$$
u_{0 m}^{(1)}(\mathbf{r})=J_{0}\left(r \sqrt{\lambda_{0 m}}\right)
$$

When solving a test problem, the coordinate origin was placed in the center of the circular domain of radius $r_{0}=2$. Point charges, modeling the researched field by using PSM, were evenly distributed on the auxiliary circle of radius $\mathrm{R}=3$. The charge $Q$, creating a known field $U_{0}(\mathbf{r})$, was located on the $X$-axis at a distance $\rho=2 r_{0}$ from the center of the domain $\Omega$. When finding eigenfunctions $u_{n m}^{(2)}(\mathbf{r})$ the charge $Q$ is moved to the axis $Y$.

Fig. 1 shows graphs of the criteria for the eigenvalues of the parameter $\lambda$. The $\mathrm{x}$-axis represents the value of $\left(\lambda-\lambda_{01}\right) / \lambda_{01}$, where $\lambda_{01}$ - the smallest eigenvalue of the boundary value problem corresponding $\mu_{01} \approx 2.405$. The ordinate axis is a value of $C / C_{\max }$, where $C_{\max }$ - the condition number of the PSM system at $\lambda=\lambda_{01}$ (curve with square markers); a relative error $\varepsilon / \varepsilon_{\max }$, where $\varepsilon_{\max ^{-}}$PSM error at $\lambda=\lambda_{01}$ (curve with round markers); or the value of $D_{\min } / \mathrm{D}$, where $D_{\min }$ - determinants (in absolute value) of the matrix system at PSM $\lambda=\lambda_{01}$ (curve with triangle markers). The calculations were performed with the number of charges, simulating the field, $N=30$. 


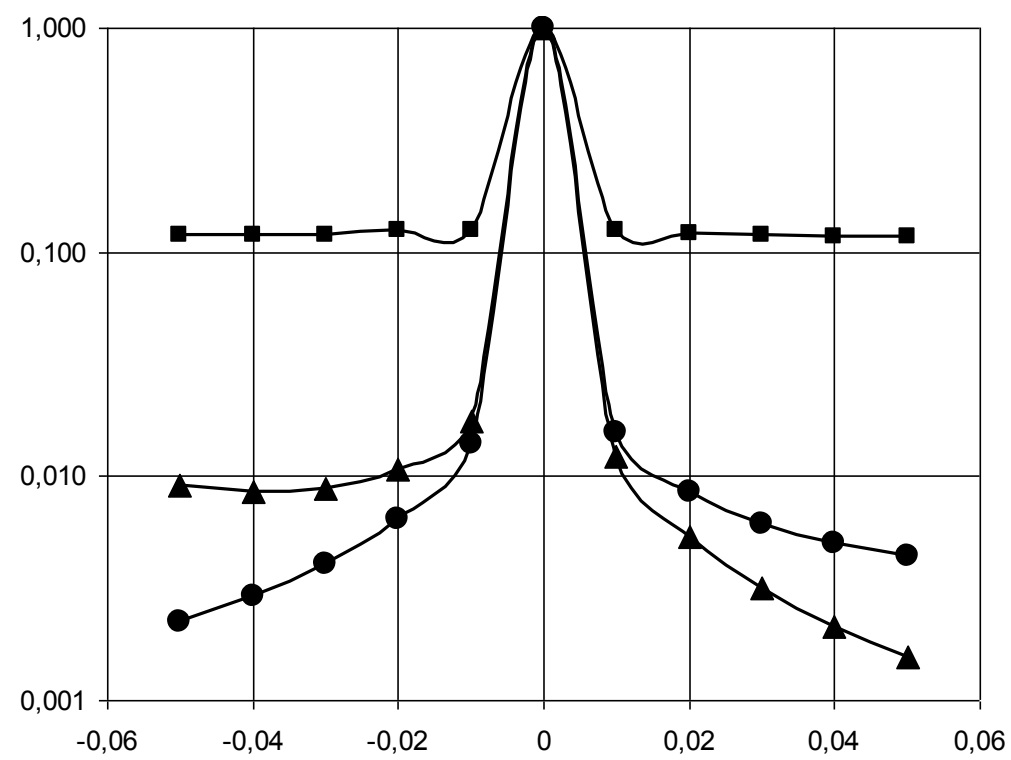

Fig. 1. Dependencies of eigenvalues criteria on the relative value of the parameter $\lambda$

As it can be seen from Fig. 1, we use the dependence of the condition number $C$ on the parameter $\lambda$, to find the eigenvalues of the problem, of the least preferred. Since the maximum of corresponding curve is expressed weakly (the maximum value differs of the minimum by less than 6 times). In addition, the change in the number conditionality takes place in a very narrow range $\Delta \lambda$ value of the parameter $\lambda\left(\Delta \lambda \approx 0.02 \lambda_{01}\right)$. Therefore, to find the eigenvalues of the boundary value problem it is advisable to use the dependency PSM error from parameter $\lambda$, since in this case it is possible to find eigenfunctions simultaneously.

Note that, the results which are shown in Fig. 1 were calculated, using the number $\mu_{01} \approx 2.405$. By substituting a more accurate value of this parameter $\mu_{01} \approx 2.4048255577$, the maximum of dependences presented in Fig. 1 become sharper. In our test problem solving we intentionally used approximate values of the eigenvalues, as in the solution of real problems in the process of finding the eigenvalues, given by step variation $\Delta \lambda$, parameter $\lambda$, which cannot be infinitesimal. In reality, we can only approach the eigenvalue. In this case eigenvalue can be found only if the step variation $\Delta \lambda$ is less than the maximum width in the corresponding dependency.

The results shown in Fig. 1 were obtained when the amount of charges, simulating the field, was $N=30$. Computational experiments showed that increasing the number $N$ of charges does not lead to significant improvement dependencies in Fig. 1. Moreover in the graph of the dependence of condition number of the PSM system from the parameter $\lambda$, the maximum becomes much less expressed. Therefore, we recommended using a small number of modeling field charges, when searching for the eigenvalues.

When searching for the following eigenvalues $\lambda_{n m}$, with large values of $n$ and $m$ the noted above features of the method are the same with one significant addition. Namely, the greater the eigenvalue, the corresponding maxima on the curves of dependence of the eigenvalues criteria on the value of the parameter $\lambda$, become narrower. Therefore, if you search for $\lambda_{01}$, as it can be seen in Fig. 1 , it is enough to set the step of the variation order $\Delta \lambda \approx 0.1 \lambda_{01}$, then searching $\lambda_{03}$, as shown by 
calculation, varying the step will have to decreased to values $\Delta \lambda \approx 0.02 \lambda_{03}$, which, of course, will increase the amount of computation.

Test example of finding the eigenvalues for three-dimensional problem. As another test example, we consider the determination of the Dirichlet problem eigenvalues for the homogeneous Helmholtz equation in a cube domain with side $\mathrm{L}=2$. For this problem, the eigenvalues are [21]

$$
\lambda_{n m k}=\pi^{2}\left(n^{2}+m^{2}+k^{2}\right) / L^{2} ; n=1,2,3, \ldots ; \quad m=1,2,3, \ldots ; \quad k=1,2,3, \ldots,
$$

and the eigenfunctions are

$$
u_{n m k}(x, y, z)=\sin (\pi n x / L) \sin (\pi m y / L) \sin (\pi k z / L) .
$$

Thus, the eigenvalues are determined by the value of the number $l=n^{2}+m^{2}+k^{2}$. The first eigenvalue, determined by $n=1 ; m=1 ; k=1 ; l=3$, the unique eigenfunction is corresponding to it. This eigenvalue is not degenerate. The next larger eigenvalue, corresponding $l=6$, has three times degenerated already.

When solving the test problem, the point charges of the modeling the researched field with the help of the PSM were evenly distributed on the surface of the auxiliary cube with rib length $L_{q}=1,3 L$. The charge $Q$, creating the known field $U_{0}(\mathbf{r})$, was located on the $X$ axis at a distance $\rho=L$ from the cube center.

The graphs of the dependence of the relative PSM error on the relative deviation of the Helmholtz parameter from the eigenvalue are shown in Fig. 2 . The value $\left(\lambda-\lambda_{0}\right) / \lambda_{0}$ is plotted along the abscissa, where $\lambda_{0}$ is the test eigenvalue of the boundary-value problem. Calculations were performed with the number $N=600$ of charges modeling the field.

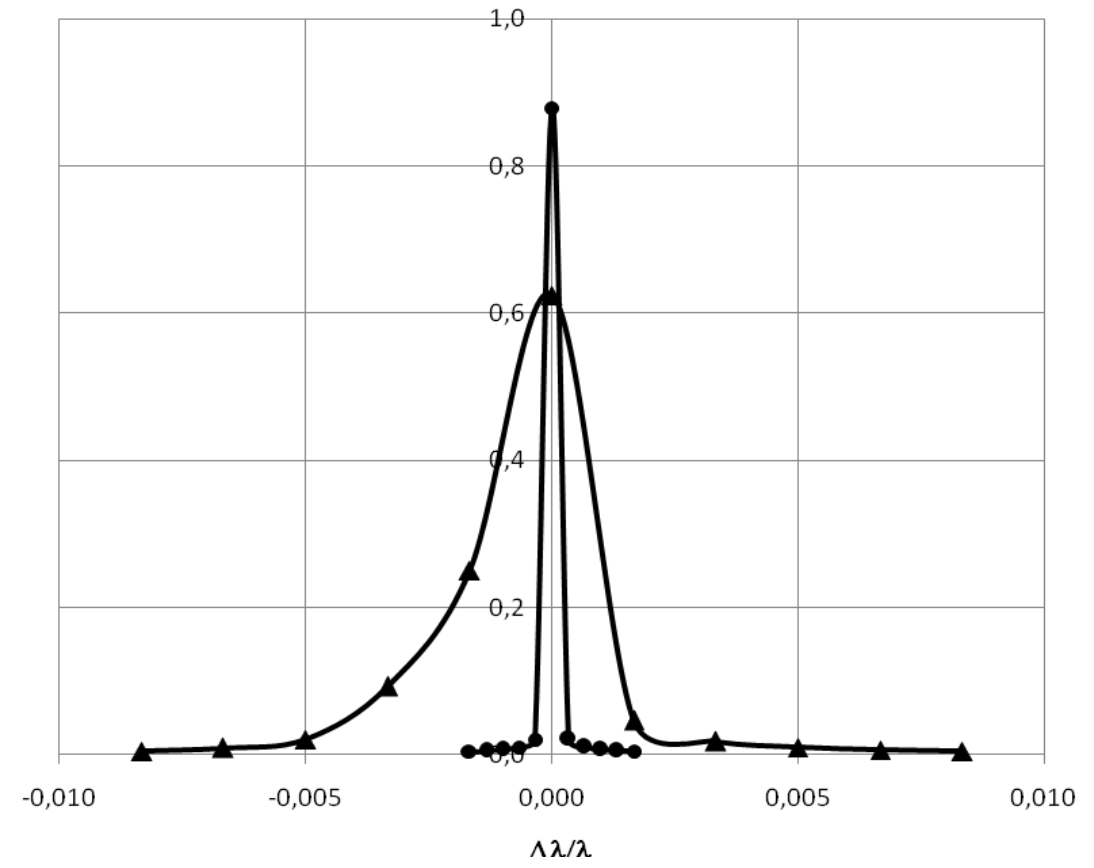

Fig. 2. Dependencies of the PSM relative error on the relative value of the parameter $\lambda$

In Fig. 2, the curve with round markers was obtained for the first eigenvalue, accoding to $l=3$; the curve with triangle markers - for the next eigenvalue corresponding to $l=6$. As it can be 
seen from Fig. 2, the curve accoding to the first eigenvalue has a sharper and higher maximum than the corresponding curve obtained for the second eigenvalue. For the subsequent eigenvalues, the maxima on the corresponding curves become more diffuse and less pronounced.

Test example of finding the eigenfunctions. After eigenvalue, example $\lambda_{01}$, was found, we can find eigenfunction of boundary value problem (7). In this case, it is necessary, to be able to control the error of the result. To assess the error of the eigenfunction $u(r)$, obtained by PSM, firstly we perform the normalization of this function, and of the known eigenfunction (9), by dividing these functions at their maximum values in the domain of solution. After this the estimated value of the

$$
\varepsilon=\max _{\mathbf{r} \in \Omega}\left|u(\mathbf{r})-u_{0 m}^{(1)}(\mathbf{r})\right| .
$$

For the eigenfunctions in Fig. 3 it is shown the dependence of the PSM error from the number of charges $\mathrm{N}$, modeling the field. The dependences, obtained for $\lambda_{01}$ (curves round markers), for $\lambda_{03}$ (curve with triangle markers) and $\lambda_{04}$ (curve with square markers), are shown in Fig. 3.

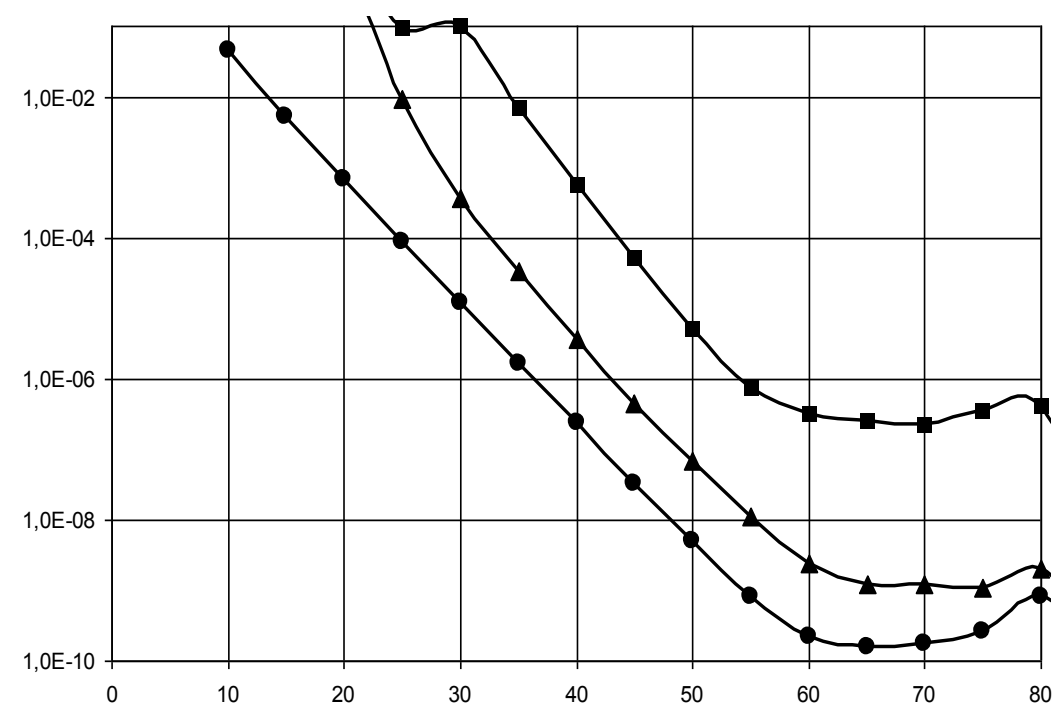

Fig. 3. Dependence of the PSM relative error for the eigenfunctions, on the number of charges $\mathrm{N}$, simulating the field.

Fig. 3 shows that the PSM relative errors are very small (up to $10^{-10}$ ) for the eigenfunctions. It is evident that PSM is characterized by the rapid exponential decrease of errors with increasing number of charges $N$. The smallest error is observed for the smallest eigenvalue. For $\lambda_{04}$ error of PSM is several orders of magnitude higher than for $\lambda_{01}$, while remaining sufficiently low (about $10^{-6}$ for $N=55$ ).

As it is noted above, the eigenvalues $\lambda_{n m}$ with $n>0$ correspond two eigenfunctions (8). In the calculation of eigenfunctions (7), using PSM, we find one of them, or their linear combination. This depends on the known solution $U_{0}(\mathbf{r})$, i.e. the position of the charge $Q$, creating a field $U_{0}(\mathbf{r})$.

Fig. 4 shows the computer screen, with the distribution of the values eigenfunction graphics along the $X$-axis from the center of the solutions domain to its boundary. The parameter $\lambda$ relied close to the property value of $\lambda_{12}$. 


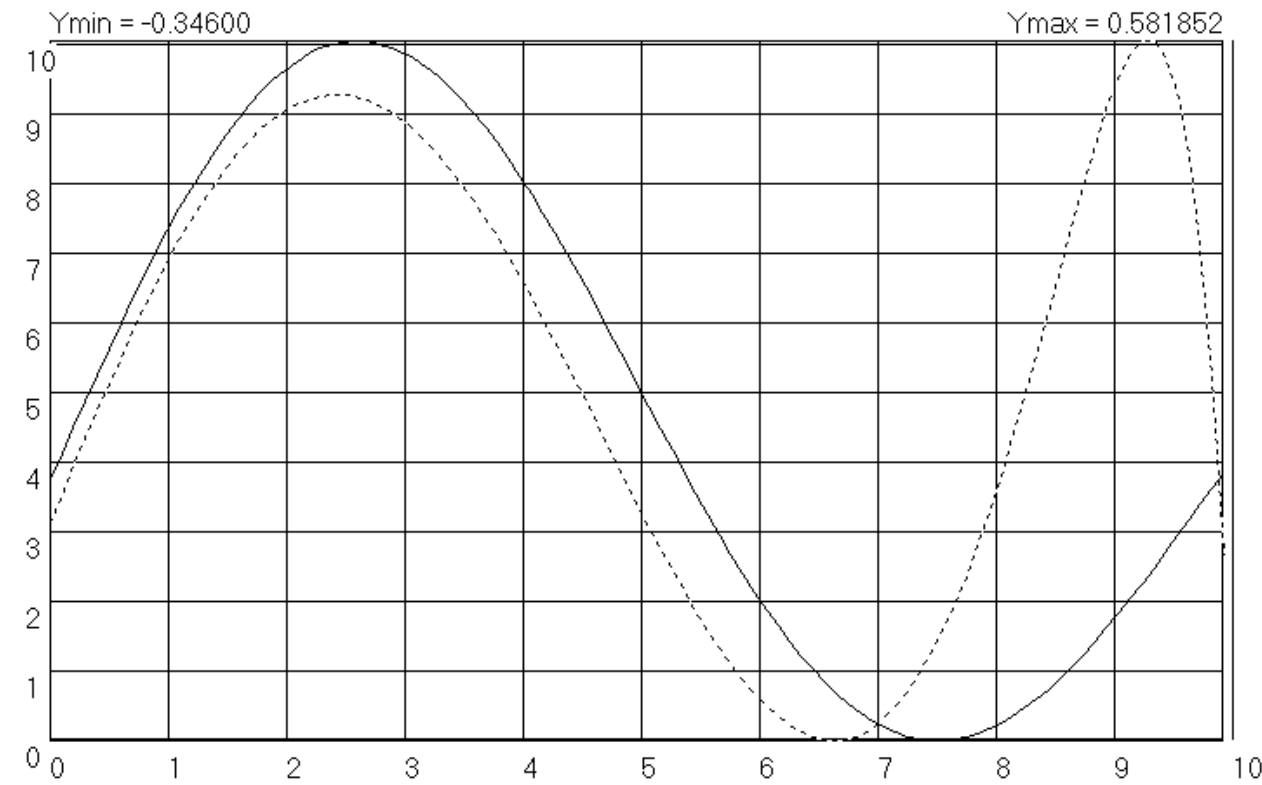

Fig. 4. Screenshot, which shows the distribution of the values eigenfunctions graphics along the $X$-axis from the center of the field of solutions domain to its boundary

The solid curve in Fig. 4 corresponds to the exact value of eigenvalue $\lambda_{12}$. The curve obtained through PSM, merges with the graph of analytical solution $u_{12}^{(1)}(\mathbf{r})$. However, a small change in a parameter $\lambda$ leads to a significant distortion of the numerical solution, as it is evident in Fig. 4, where the dashed curve was obtained at $\lambda=1.01 \lambda_{12}$.

In modeling the eigenfunctions, as before, the charge $Q$ creating the field $U_{0}(\mathbf{r})$ was located on the $X$ axis at a distance $\rho=2 r_{0}$ from the center of the domain $\Omega$. In doing so, we obtained the eigenfunction $u_{12}^{(1)}(\mathbf{r})$. When the charge $Q$, generating the field $U_{0}(\mathbf{r})$, was moved to the axis $Y$, the eigenfunction $u_{12}^{(2)}(\mathbf{r})$ is modeled . This is due to the fact that the symmetry of the eigenfunction agrees with the symmetry of the field $U_{0}(\mathbf{r})$.

When solving the three-dimensional boundary value problem in the volume of a cube, the choice of the charge $Q$ location creating the field $U_{0}(\mathbf{r})$ also determines one or another eigenfunction. For example, for the second eigenvalue, when the charge $Q$ is located on the $X$ axis, the eigenfunction $u_{211}(x, y, z)$ is determined. To find the eigenfunction $u_{121}(x, y, z), Q$ must be placed on the $Y$ axis, and for the eigenfunction $u_{112}(x, y, z)$ - on the $Z$ axis.

Conclusion. The above examples of test problems demonstrate the effectiveness of using PSM in solving problems of finding the eigenvalues and eigenfunctions of the Helmholtz equation. Taking into account that these tasks can be performed using a small number of point charges (no more than a few tens in solving two-dimensional problems, several hundred - for three-dimensional problems) it should be recognized that the method is very economical. The difficulties associated with the multiplicity of eigenvalues, are easily overcome by the use of several different $U_{0}(\mathbf{r})$ of the known solutions, which do not necessarily have to match the field of a point charge, but must be consistent with the symmetry of the required eigenfunctions. 


\section{References}

1. Fairweather G. The method of fundamental solutions for elliptic boundary value problems / G. Fairweather, A. Karageorghis // Ad. Vol. Comput. Math. - 1998. - Vol. 9. - P. 69-95.

2. Alves C.J.S. A new method of fundamental solutions applied to nonhomogeneous elliptic problems / C.J.S. Alves, C.S. Chen // Advances in Computational Mathematics. - 2005. - Vol. 23 P. 125-142.

3. Knyazev, S.Y. Ustoychivoct' i skhodimost' metoda tochechnykh istochnikov polya pri chislennom reshenii kraevykh zadach dlya uravneniya Laplasa. [Stability and convergence of the point sources method in the numerical solution of boundary value problems for the Laplace equation.] Izv. vuzov. Electromechanics, 2010, no. 1, pp. 3-12 (in Russian).

4. Knyazev, S.Y., Shcherbakova, E.E., Engibaryan, A.A. Chislennoe reshenie kraevykh zadach dlya uravneniya Puassona metodom tochechnykh istochnikov polya. [Numerical solution of boundary value problems for the Poisson equation by the point sources method.] Vestnik of Don State Technical University, 2014, vol. 14, no. 2(77), pp. 15-20 (in Russian).

5. Knyazev, S.Y., Shcherbakova, E.E. Reshenie trekhmernykh kraevykh zadach dlya uravneniy Laplasa s pomoshchyu metoda diskretnykh istochnikov polya. [The decision of the threedimensional boundary value problems for the Laplace equation using the method of discrete sources of the field.] Izvestiya vysshikh uchebnykh zavedeniy. Electromechanics, 2015, no. 5, pp. 25-30 (in Russian).

6. Bahvalov, Y.A., Knyazev S.Y., Shcherbakov, A.A., Shcherbakova, E.E. Pogreshnost' metoda tochechnykh istochnikov pri modelirovanii potentsial'nykh poley $v$ oblastyakh $s$ razlichnoy konfiguratsiey. [Accuracy of the point sources method in the modeling of potential fields in areas with different configurations.] Izvestiya vysshikh uchebnykh zavedeniy. Electromechanics, 2012, no. 5, pp. 17-21 (in Russian).

7. Knyazev, S.Y., Shcherbakova, E.E., Zaichenko, A.N. Sravnitel'ny analiz dvykh variantov metoda kollokatsiy pri chislennom modelirovanii potentsial'nykh poley. [Comparative analysis of two variants of the collocation method for numerical modeling of potential fields.] Izvestiya vysshikh uchebnykh zavedeniy. Electromechanics, 2014, no. 1, pp. 17-19 (in Russian).

8. Knyazev, S.Y., Shcherbakova, E.E. Reshenie zadach teplo- $i$ massoperenosa $s$ pomoshch'yu metoda tochechnykh istochnikov polya. [The solution of problems of heat and mass transfer by the point sources method. Proceedings of the higher educational institutions.] NorthCaucasian region. Series: Engineering, 2006, no. 4, pp. 43-47 (in Russian).

9. Knyazev, S.Y., Pustovoyt, V.N., Shcherbakova, E.E. Modelirovanie poley uprugikh deformatsiy s primeneniem metoda tochechnykh istochnikov. [Modeling of elastic strain fields using the point sources method.] Vestnik of Don State Technical University, 2015, vol. 15, no. 1 (80), pp. 29- 38 (in Russian).

10. Knyazev, S.Y., Pustovoyt, V.N., Shcherbakova, E.E. Modelirovanie trekhmernykh poley uprugikh deformatsiy s pomoshch'yu metoda tochechnykh istochnikov. [Simulation of threedimensional fields of elastic deformation by the point sources method.] Vestnik of Don State Technical University, 2015, vol. 15, no. 4 (83), pp. 13- 23 (in Russian).

11. Knyazev, S.Y., Shcherbakova, E.E., Shcherbakov, A.A. Sravnitel'ny analiz razlichnykh variantov ispol'zovaniya metoda tochechnykh istochnikov polya pri modelirovanii temperaturnykh poley. [A comparative analysis for different variants of the point sources method in the temperature fields simulation.] Fiziko-matematicheskoe modelirovanie system: Materialy XII mezhdunar. semi- 
nara. [Physical and mathematical modeling of systems: Proceedings of XII Intern. workshop.] Voronezh, Voronezh. state. tehn. university, 2014, pp. 52-56 (in Russian).

12. Lunin, L.S., Knyazev, S.Y., Seredin, B.M., Poluhin, A.S., Shcherbakova, E.E. Issledovanie stabil'nosti termomigratsii ansamblya lineynykh zon $s$ pomoshch'yu trekhmernoy komp'yuternoy modeli, postroennoy na osnove metoda tochechnykh istochnikov polya. [Stability study of linear thermal migration zones ensemble using three-dimensional computer model, built on the basis of the point sources method. Vestnik Yuzhnogo nauchnogo tsentra, 2015, vol. 11, no. 4, pp. 9-15 (in Russian).

13. Knyazev, S.Y., Shcherbakova, E.E., Shcherbakov, A.A. Matematicheskoe modelirovanie poley uprugikh deformatsiy metodom tochechnykh istochnikov polya. [Mathematical modeling of elastic deformation fields by the point sources method. Mathematical methods in engineering and technology.] MMTT, 2015, no. 5 (75), pp. 21-23 (in Russian).

14. Knyazev, S.Y., Shcherbakova, E.E., Shcherbakov, A.A. Komp'yuternoe modelirovanie potentsial'nykh poley metodom tochechnykh istochnikov: monografiya. [Computer modeling of potential fields by the point sources method: a monograph.] Rostov-on-Don, Publishing Center DSTU, 2012, 156 p (in Russian).

15. Knyazev, S.Y. Metod tochechnykh istochnikov dlya komp'yuternogo modelirovaniya fizichrskikh poley $v$ zadachakh s podvizhnymi granitsami: diss. .... doktora tekhn. nauk. [The point sources method for computer modeling of physical fields in problems with moving boundaries: dissertation ... doctor of technical sciences.] Novocherkassk, 2011, 342 p (in Russian).

16. Knyazev, S.Y., Shcherbakova, E.E. Chislennoe issledovanie stabil'nosti termomigratsii ploskikh zon. [Numerical study of thermal stability of the flat-band migration.] Izvestiya vysshikh uchebnykh zavedeniy. Electromechanics, 2007, no. 1, pp. 14-19 (in Russian).

17. Bahvalov, Y.A., Knyazev, S.Y., Shcherbakov, A.A. Matematicheskoe modelirovanie fizicheskikh poley metodom tochechnykh istochnikov. [Mathematical modeling of physical fields by the point sources method.] Izvestiya Rossiyskoy akademii nauk. Seriya fizicheskaya, 2008, vol. 72, no. 9, pp. 1259-1261 (in Russian).

18. Knyazev, S.Y. Chislennoe reshenie uravneniy Puassona i Gelmgoltsa s pomoshch'yu metoda tochechnykh istochnikov. [Numerical solution of Poisson and Helmholtz equations using the point sources method.] Izvestiya vuzov, Electromechanics, 2007, no. 2, pp. 77-78 (in Russian).

19. Knyazev, S.Y., Shcherbakova, E.E., Zaichenko, A.N. Chislennoe reshenie kraevykh zadach dlya neodnorodnykh uravneniy Gelmgoltsa metodom tochechnykh istochnikov polya. [Numerical solution for inhomogeneous Helmholtz equation by the point sources method.] Izvestiya vysshikh uchebnykh zavedeniy. Electromechanics, 2014, no. 4, pp. 14-19 (in Russian).

20. Knyazev, S.Y. Integral'noe uravnenie dlya chislennogo resheniya statsionarnykh kvantovo-mekhanicheskikh zadach. [Integral equation for the numerical solution of a stationary quantum mechanical tasks] Vestnik of Don State Technical University, 2016, vol. 16, no. 3 (86), pp. 79-86 (in Russian).

21. Knyazev S.Yu., Shcherbakova E.E. Method for numerical solution of the stationary Schrödinger equation. Russian Physics Journal, 2017, vol. 59, no 10, pp. 1616-1622.

22. Abramovitz, A., Stigan I. Spravochnik po spetsial'nym funktsiyam. [Special Function Manual.] Moscow, Science, 1979, 832 p. (in Russian)

23. Polyanin, A.D. Spravochnik po lineynym uravneniyam matematicheskoy fiziki. [Handbook of linear equations of mathematical physics.] Moscow, FIZMATLIT, 2001, 576 p. (in Russian). 
Author:

Shcherbakova, Elena E., associate professor of the Material Physics and Applied Hylology Department, Don State Technical University (RF,344000, Rostov-on-Don, Gagarin sq., 1), Cand. Sci. (Eng.), associate professor, ORCID : http://orcid.org/0000-0002-9239-1955

УДК 519.632; 539.182

Решение задач на собственные значения и собственные функции для уравнения Гельмгольца методом точечных источников поля*

\section{Е. Е. Щербакова ${ }^{* *}$}

Донской государственный технический университет, г. Ростов-на-Дону, Российская Федерация

Разработан способ решения задач вычисления собственных значений и собственных функций для уравнения Гельмгольца в областях с произвольной конфигурацией. При разработке способа численного решения задач используется метод точечных источников поля (МТИ). Предлагаемый способ основан на анализе числа обусловленности системы МТИ или погрешности численного решения задачи. Вводится понятие «критерий собственных значений». Результатом работы является разработанный эффективный способ - алгоритм решения задач на нахождение собственных значений и собственных функций для уравнения Гельмгольца. Показано, что при приближении параметра Гельмгольца к собственному значению задачи число обусловленности системы МТИ и погрешность численного решения резко возрастают. Определив зависимость погрешности численного решения задачи или числа обусловленности системы МТИ от параметра Гельмгольца, можно по расположению максимума для полученных зависимостей найти собственные значения уравнения Гельмгольца в заданной области. После нахождения собственного значения можно приступить к нахождению собственных функций. При этом, если собственное значение оказывается вырожденным, то есть ему соответствует несколько собственных функций, то, с учетом симметрии области решения, возможно нахождение всех собственных функций. Приведены результаты решения тестовых двумерных и трехмерных задач, на основании которых делается вывод об эффективности предложенного метода.

Ключевые слова: метод точечных источников, собственные значения, собственные функции, уравнение Гельмгольца, фундаментальное решение, метод фундаментальных решений.

\section{Автор:}

Щербакова Елена Евгеньевна, доцент каф. «Физическое и прикладное материаловедение» Донского государственного технического университета (РФ, 344000, Ростов-на-Дону, пл. Гагарина, 1), кандидат технических наук, доцент, ORCID : $\underline{\text { http://orcid.org/0000-0002-9239-1955 }}$

\footnotetext{
* Работа выполнена в рамках инициативной НИР

E-mail: Sherbakovaee@mail.ru
} 